\title{
CREB Participates in Paclitaxel-Induced Neuropathic Pain Genesis Through Transcriptional Activation of Dnmt3a in Primary Sensory Neurons
}

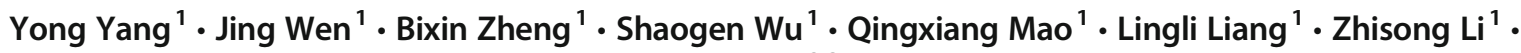 \\ Thomas Bachmann ${ }^{1}$. Alex Bekker ${ }^{1}$ - Yuan-Xiang Tao ${ }^{1,2,3}$ (1)
}

Accepted: 4 September 2020 / Published online: 13 October 2020

(C) The American Society for Experimental NeuroTherapeutics, Inc. 2020

\begin{abstract}
Chemotherapy-induced peripheral neuropathic pain (CIPNP) often occurs in cancer patients treated with antineoplastic drugs. Therapeutic management of CIPNP is very limited, at least in part due to the largely unknown mechanisms that underlie CIPNP genesis. Here, we showed that systemic administration of the chemotherapeutic drug paclitaxel significantly and timedependently increased the levels of cyclic AMP response element-binding protein (CREB) in dorsal root ganglion (DRG) neurons. Blocking this increase through DRG microinjection of Creb siRNA attenuated paclitaxel-induced mechanical, heat, and cold nociceptive hypersensitivities. Mimicking this increase through DRG microinjection of the adeno-associated virus 5 expressing full-length Creb mRNA led to enhanced responses to basal mechanical, heat, and cold stimuli in mice in absence of paclitaxel treatment. Mechanically, paclitaxel-induced increase of DRG CREB protein augmented Dnmt $3 a$ promoter activity and participated in the paclitaxel-induced upregulation of DNMT3a protein in the DRG. CREB overexpression also elevated the expression of DNMT3a in in vivo and in vitro DRG neurons of naïve mice. Given that DNMT3a is an endogenous instigator of CIPNP and that CREB co-expresses with DNMT3a in DRG neurons, CREB may be a key player in CIPNP through transcriptional activation of the Dnmt3a gene in primary sensory neurons. CREB is thus a likely potential target for the therapeutic management of this disorder.
\end{abstract}

Key Words Neuropathic pain $\cdot$ paclitaxel $\cdot$ CREB $\cdot$ DNMT3a.

Chemotherapeutic drug-induced peripheral neuropathic pain (CIPNP) is a common adverse effect in patients treated with anticancer drugs. Paclitaxel, a frontline chemotherapeutic agent used to treat many solid tumors, causes about 40 to $60 \%$ of CIPNP cases [1]. Its painful and distressing symptoms

Yong Yang, Jing Wen and Bixin Zheng contributed equally to this work.

Yuan-Xiang Tao

yuanxiang.tao@njms.rutgers.edu

1 Department of Anesthesiology, New Jersey Medical School, Rutgers, The State University of New Jersey, 185 S. Orange Ave., MSB, F-661, Newark, NJ 07103, USA

2 Department of Physiology, Pharmacology \& Neuroscience, New Jersey Medical School, Rutgers, The State University of New Jersey, Newark, NJ 07103, USA

3 Department of Cell Biology \& Molecular Medicine, New Jersey Medical School, Rutgers, The State University of New Jersey, Newark, NJ 07103, USA often lead to a discontinuation of antineoplastic therapy, resulting in a reduction in survival rates. Moreover, these symptoms significantly affect the quality of life of cancer survivors. Unfortunately, current treatments for CIPNP in cancer patients are very limited at least in part due to largely unknown mechanisms by which chemotherapy drugs cause pain and neuropathy. Chemotherapeutic drugs may cause ectopic discharges in the neurons of the dorsal root ganglion (DRG) [2-5]. This ectopic spontaneous activity, which was identified as a CIPNP trigger [2-5], has been demonstrated to be associated with transcriptional and translational changes in gene expression of ion channels, receptors, and enzymes in the DRG [2, 3, 5-7]. Thus, understanding how chemotherapeutic drugs drive these changes may provide a new avenue for the treatment of CIPNP.

Cyclic AMP (cAMP)-response element-binding protein (CREB), a nuclear transcription factor, regulates gene expression through its binding to DNA sequences (called cAMP response elements) of certain gene promotors [8]. CREB has 
a well-documented role in neuronal plasticity and the formation of spatial memory in the brain and is implicated in the pathology of neurological diseases $[9,10]$. Accumulating evidence suggests a function of DRG CREB in chronic pain genesis. Level of phosphorylated-CREB (p-CREB) is significantly increased in DRG neurons after peripheral inflammation, peripheral nerve injury, intraperitoneal injection of streptozotocin, or chronic morphine exposure [11-16]. Activated p-CREB is expressed in CGRP-, TRPV1-, or SPpositive DRG neurons [12, 13, 17]. CREB participates in the TRPV1-mediated upregulation of CGRP after inflammation and in PGE2-induced BDNF synthesis after peripheral nerve injury in DRG neurons $[17,18]$. CREB is a downstream factor of the $\mathrm{Ca}^{2+} /$ calmodulin-dependent protein kinase II or mitogen-activated protein kinase in the DRG under conditions of cancer pain or peripheral nerve injury-induced neuropathic pain [19-21]. Intrathecal injection of anti-CREB antibody or CREB antisense oligonucleotides blocks the chronic constriction injury-induced pain hypersensitivities likely through the regulation of the NR1 and NR2B subunits of the NMDAR or c-Fos, GFAP, CX3CR1, and IBA-1 in the spinal cord dorsal horn [22, 23]. However, whether DRG CREB is involved in these pathways is unclear. Moreover, whether DRG CREB participates in CIPNP is unknown.

In the present study, we first examined whether CREB was activated and upregulated in DRG neurons after paclitaxel injection. We then investigated whether blocking increased CREB in DRG affected paclitaxel-induced CIPNP. We also observed whether DRG overexpression of CREB elicited CIPNP-like symptoms in the absence of paclitaxel. Finally, we elucidated how activated CREB participated in paclitaxelinduced CIPNP.

\section{Materials and Methods}

\section{Animal Preparation}

Adult male CD1 mice (male, 7-8 weeks) were purchased from Charles River Laboratories (Raleigh, NC) and were housed in the central housing facility under a standard 12-h light/12-h dark cycle with free access to food and water. The Institutional Animal Care and Use Committee of Rutgers New Jersey Medical School approved all procedures used in this study. Additionally, all procedures were consistent with ethical guidelines produced by the National Institutes of Health and the International Association for the Study of Pain. All efforts were made to minimize the suffering of animals and reduce the number of animals used. To minimize intra- and interindividual variability in behavioral outcome measurements, animals were acclimated for $1-2$ days before behavioral testing. The experimenters/observers were blinded to treatment conditions.

\section{CIPNP Model}

The mouse model of CIPNP was conducted as described previously $[6,7]$. Briefly, paclitaxel $(6 \mathrm{mg} / \mathrm{ml}$ in $50 \%$ Cremophor El (Sigma Aldrich, St. Louis, MO)) and 50\% ethanol (SigmaAldrich) was diluted in sterile saline to a final concentration of $0.4 \mathrm{mg} / \mathrm{ml}$ and administered intraperitoneally at a dose of $4 \mathrm{mg} / \mathrm{kg}$ every other day for 8 consecutive days. Vehicle 1 was prepared as the same as paclitaxel preparation described above except for paclitaxel.

\section{siRNA Preparation}

Creb siRNA (catalog number: sc-35111; Santa Cruz Biotechnology, Inc., Dallas, TX) and negative control scrambled siRNA (catalog number: sc-37007; Santa Cruz Biotechnology, Inc.) were prepared as described previously [24-26]. Briefly, $2 \mu \mathrm{l}$ of siRNA $(160 \mu \mathrm{M})$ was first diluted with $1 \mu$ l of $20 \%$ glucose solution (in $\mathrm{dH}_{2} \mathrm{O}$ ). After gentle mixing, $1 \mu \mathrm{l}$ of TurboFect in vivo transfection reagent (Thermo Fisher Scientific Inc.) was added. After incubating for 15-20 $\mathrm{min}$ at room temperature, the diluted siRNA solution was ready for the use. Vehicle 2 was prepared as the same as siRNA preparation described above except for siRNA.

\section{Plasmid Construction and Virus Preparation}

In accordance with our previously published protocols [27, 28], a 498-bp fragment from the Dnmt3a gene promotor region (including CREB-binding motif) was amplified by PCR from genomic DNA. The sequences of primers used are listed in Table 1. The PCR products were subcloned into the KpnI and HindIII restriction sites of the pGL3-Basic vector (Promega, Madison, WI). Mouse full-length CREB cDNA was reverse-transcripted and amplified from total RNA of mouse DRG using the SuperScript III One-Step RT-qPCR System with the Platinum Taq High Fidelity Kit (Invitrogen/ ThermoFisher Scientific, Grand Island, NY) and primers (Table 1). Fragments harboring CREB were ligated into proviral plasmids using the BspEI and NotI restriction sites. The resulting vector expressed CREB under the control of the cytomegalovirus promotor. The recombinant clones were verified using DNA sequencing. The AAV5 particles were prepared using AAV5 Helper Free Packaging System (Cell Biolabs, Inc., San Diego, CA). The AAV5 particles were purified using the AAV pro Purification Kit (Takara, Mountain View, CA). AAV5-EGFP used as a control was prepared as same procedure as described above except for CREB.

\section{DRG Microinjection}

DRG microinjection was carried out as previously described $[28,29]$ with minor modification. Briefly, a dorsal midline 
Table 1 Primers used

\begin{tabular}{ll}
\hline Names & Sequences $\left(5^{\prime}\right.$ to $\left.3^{\prime}\right)$ \\
\hline ChIP PCR & \\
Dnmt3a $\mathrm{F}$ & CCAACTGTGACAGAGCCTCA \\
Dnmt $3 a \mathrm{R}$ & ACAGCAACTGTCAGGGGACT \\
Luciferase & \\
Dnmt3a $\mathrm{F}$ & ATAGGTACCCCAACTGTGACAGAGCCTCA \\
Dnmt3a $\mathrm{R}$ & ATCAAGCTTTCCAGAGGACCTGGGTGTAG \\
Cloning & \\
$C r e b-R T-F$ & GGAGCTTGTACCACCGGTAA \\
$C r e b-R T-R$ & CTTGAGGGCAGAAGTGGAAG \\
$C r e b-N-P C R-F$ & ATATCCGGAGCCACCATGACCATGGAATCTGGA \\
$C r e b-N-P C R-R$ & CGCCAGCGGCCGCAATTAATCTGATTTGTGG \\
\hline
\end{tabular}

$F$ forward, $N$ nest, $R$ reverse, $P C R$ polymerase chain reaction, $R T$ : reverse transcription

incision was made in the lower back region, and the lumbar articular processes were exposed and then removed. The exposed L3-4 DRGs were injected with the siRNA $(1 \mu \mathrm{l} / \mathrm{DRG}$, $40 \mu \mathrm{M})$, vehicle, or virus $\left(1 \mu \mathrm{l} / \mathrm{DRG}, 5.5 \times 10^{12}\right)$ solutions through a glass micropipette connected to a Hamilton syringe. The pipette was removed $10 \mathrm{~min}$ after injection. The surgical field was irrigated with sterile saline and the skin incision closed with wound clips.

\section{Behavioral Testing}

Mechanical, cold, and heat tests, as well as the conditional place preference (CPP) test and locomotor performance assessments, were performed as previously described [30-32]. Each behavioral test for evoked pain was carried out at 30-60min intervals.

Mechanical behavioral testing was carried out first. Briefly, each mouse was placed individually in a Plexiglas chamber on an elevated mesh screen. Two calibrated von Frey filaments (0.07 and $0.4 \mathrm{~g}$, Stoelting Co., Wool Dale, IL) were applied to each hind paw 10 times at intervals of $5 \mathrm{~min}$. A quick withdrawal of the paw was regarded as a positive response. Paw withdrawal frequency was calculated by dividing the number of positive paw withdrawal responses by 10 trials.

Heat behavioral testing was then performed. In brief, each animal was placed in a Plexiglas chamber on a glass plate. Radiant heat from a Model 336 Analgesic Meter (IITC Inc./ Life Science Instruments, Woodland Hills, CA, USA) was applied by aiming a beam of light through a hole in the light box through the glass plate to the middle of the plantar surface of each hind paw. When the animal lifted its paw in response to the heat, the light beam was automatically turned off. The time from the start of each light beam to the time of foot lift was defined as the paw withdrawal latency. Each trial was repeated five times at 5-min intervals for each side. A cutoff time of $20 \mathrm{~s}$ was used to avoid tissue damage to the hind paws.
Cold behavioral testing was carried out last. Each mouse was placed in a Plexiglas chamber on a cold aluminum plate, the temperature of which was set at $0{ }^{\circ} \mathrm{C}$ and monitored continuously by a thermometer. The length of time between the placement of the hind paw on the plate and the animal jumping, with or without paw licking and flinching, was defined as the paw withdrawal latency. Ten-minute recovery was allowed between 3 repeated trials. A cutoff time of $20 \mathrm{~s}$ was used to avoid paw tissue damage.

CPP testing was carried out 7 weeks after DRG microinjection of the virus. Briefly, mice were first preconditioned with full access to two different Plexiglas chambers connected through an internal door (Med Associates Inc.) for $30 \mathrm{~min}$ daily for 3 days. The conditioning protocol was performed on the following 3 days with the internal door closed. The mice first received an intrathecal injection of saline $(5 \mu \mathrm{l})$ specifically paired with one conditioning chamber in the morning. Six hours later, lidocaine $(0.4 \%$ in $5 \mu$ l of saline $)$ was given intrathecally, paired with another conditioning chamber in the afternoon. The injection order of saline and lidocaine was switched each consecutive day. On the test day, the mice were placed in one chamber with free access to both chambers. The duration of time that each mouse spent in each chamber was recorded for $15 \mathrm{~min}$. Difference scores were calculated by subtracting preconditioning time from test time spent in the lidocaine chamber.

Locomotor function, including placing, grasping, and righting reflexes, was examined before tissues were collected. (1) Placing reflex: the placed positions of the hind limbs were slightly lower than those of the forelimbs, and the dorsal surfaces of the hind paws were brought into contact with the edge of a table. Whether the hind paws were placed on the table surface reflexively was recorded; (2) grasping reflex: After the animal was placed on a wire grid, whether the hind paws grasped the wire on contact was recorded; (3) righting reflex: when the animal was placed on its back on a flat surface, 
whether it immediately assumed the normal upright position was recorded. Each trial was repeated five times at 5-min interval and the scores for each reflex were recorded based on counts of each normal reflex.

\section{DRG Neuron Culture and Transfection}

Primary DRG neuronal cultures and viral transfection were carried out as previously described [27, 28, 31, 33, 34]. Briefly, after adult mice were euthanized with isoflurane, all DRGs were collected in cold Neurobasal Medium (Gibco/ ThermoFisher Scientific) with $10 \%$ fetal bovine serum (JR Scientific, Woodland, CA), 100 units/ml penicillin, and $100 \mu \mathrm{g} / \mathrm{ml}$ streptomycin (Quality Biological, Gaithersburg, $\mathrm{MD})$ and then treated with enzyme solution $(5 \mathrm{mg} / \mathrm{ml}$ dispase, $1 \mathrm{mg} / \mathrm{ml}$ collagenase type I in Hanks' balanced salt solution (HBSS)) without $\mathrm{Ca}^{2+}$ and $\mathrm{Mg}^{2+}$ (Gibco/ThermoFisher Scientific). After trituration and centrifugation, dissociated cells were resuspended in mixed Neurobasal Medium and plated in a six-well plate coated with $50 \mu \mathrm{g} / \mathrm{ml}$ poly-D-lysine (Sigma, St. Louis, MO). The cells were incubated at $95 \% \mathrm{O}_{2}$, $5 \% \mathrm{CO}_{2}$, and $37^{\circ} \mathrm{C}$. One day later, $4-6 \mu$ of virus (titer $\geq 1 \times$ $10^{12} / \mathrm{ml}$ ) or $50 \mathrm{nM}$ siRNA was added to each well. The neurons were collected 3 days later.

\section{Western Blotting Assay}

Four unilateral mouse DRGs were pooled together to achieve enough protein. DRGs or spinal cord were homogenized and the cultured cells ultrasonicated in chilled lysis buffer $(10 \mathrm{mM}$ Tris, $1 \mathrm{mM}$ phenylmethylsulfonyl fluoride, $5 \mathrm{mM} \mathrm{MgCl}$, $5 \mathrm{mM}$ EGTA, $1 \mathrm{mM}$ EDTA, $1 \mathrm{mM}$ DTT, $40 \mu \mathrm{M}$ leupeptin, $250 \mathrm{mM}$ sucrose). After centrifugation at $4{ }^{\circ} \mathrm{C}$ for $15 \mathrm{~min}$ at $1000 \mathrm{~g}$, the supernatant was collected for cytosolic proteins and the pellet for nuclear proteins. The amounts of proteins in the samples were measured using the Bio-Rad protein assay (Bio-Rad). The samples were heated at $99^{\circ} \mathrm{C}$ for $5 \mathrm{~min}$ and loaded onto a $4-15 \%$ stacking $/ 7.5 \%$ separating SDSpolyacrylamide gel (Bio-Rad Laboratories). The proteins were then electrophoretically transferred onto a polyvinylidene difluoride membrane (Bio-Rad Laboratories). After the membranes were blocked with $3 \%$ nonfat milk in Tris-buffered saline containing $0.1 \%$ Tween- 20 for $1 \mathrm{~h}$, the following primary antibodies were applied: mouse anti-CREB (1:1000, Cell signaling, Danvers, MA), rabbit anti-DNMT3a (1:1000, Cell Signaling), rabbit anti-GAPDH (1:1000, Santa Cruz, Dallas, Texas), mouse anti-p-CREB(1:500, Millipore), rabbit anti-C-Jun (1:500, GenScript, A00197), rabbit antihistone H3 (1:1000, Cell Signaling), and rabbit anti-OCT1 (1:1000, Abcam, 178869). The proteins were detected by horseradish peroxidase-conjugated anti-mouse or anti-rabbit secondary antibody (1:3000, Jackson ImmunoResearch) and visualized by western peroxide reagent with luminol/enhancer reagent (Clarity Western ECL Substrate, Bio-Rad) using the ChemiDoc XRS System with Image Lab software (Bio-Rad). The intensity of blots was quantified with densitometry using Image Lab software (Bio-Rad). All cytosolic protein bands were normalized to GAPDH and all nuclear proteins to total histone $\mathrm{H} 3$.

\section{Immunofluorescence Histochemistry}

Double-labeled immunofluorescence histochemistry was carried out as described previously [24, 27, 28, 35]. Briefly, after being deeply anesthetized with isoflurane, mice were perfused through the left ventricle with $50 \mathrm{~mL}$ of $0.01 \mathrm{M}$ phosphatebuffered saline (PBS, pH 7.4) followed by $100 \mathrm{~mL}$ of $4 \%$ paraformaldehyde in $0.01 \mathrm{M}$ phosphate buffer ( $\mathrm{pH}$ 7.4). Bilateral L3/4 DRGs were harvested, postfixed in the same fixative solution at $4{ }^{\circ} \mathrm{C}$ for $3-5 \mathrm{~h}$, and dehydrated in $30 \%$ sucrose in $0.01 \mathrm{M}$ PBS overnight. DRG was cut into $20-\mu \mathrm{m}$ sections using a cryostat. The sections were first incubated in a blocking buffer (0.01 M PBS containing $0.3 \%$ Triton X-100 and $3 \%$ goat serum) for $1 \mathrm{~h}$ at room temperature, and then incubated with a mixture of primary mouse anti-CREB (1:500, Cell Signaling) and chicken anti- $\beta$-tubulin III (1:1000, Abcam) or rabbit anti-DNMT3a (1:300, Abcam) overnight at $4{ }^{\circ} \mathrm{C}$. The sections were then incubated with a mixture of goat anti-rabbit IgG conjugated with Cy3 (1:200, Jackson ImmunoResearch) and donkey anti-mouse IgG conjugated with Cy2 (1:200, Jackson ImmunoResearch) or with a mixture of goat anti-mouse IgG conjugated with Cy3 (1:200, Jackson ImmunoResearch) and donkey anti-chicken IgG conjugated with Cy2 (1:200, Jackson ImmunoResearch) for $1 \mathrm{~h}$ at $37^{\circ} \mathrm{C}$. Control experiments were carried out in parallel as reported before [24, 27, 28, 35]. All immunofluorescencelabeled images were examined using a Leica DMI 4000 fluorescence microscope and images captured with a DFC365FX camera (Leica, Germany). Double-labeled neurons were quantified.

\section{Chromatin Immunoprecipitation Assay}

Chromatin immunoprecipitation (ChIP) assays were conducted using the EZ Megana ChIP G-chromatin immunoprecipitation Kit (Upstate/EMD Millipore, Darmstadt, Germany) as described previously $[27,28]$. The homogenized solution of DRGs was cross-linked with $1 \%$ formaldehyde for $10 \mathrm{~min}$ at room temperature. The reaction was terminated by the addition of $0.25 \mathrm{M}$ glycine. After centrifugation, the collected pellet was lysed by SDS lysis buffer with a protease inhibitor cocktail and sonicated until the DNA was broken into fragments with a mean length of 200 to $1000 \mathrm{bp}$. After the samples were pre-cleaned with protein $\mathrm{G}$ agarose, they were subjected to immunoprecipitation overnight at $4{ }^{\circ} \mathrm{C}$ with $2 \mu \mathrm{g}$ of rabbit- 
CREB antibody (Abcam) or with $2 \mu \mathrm{g}$ of normal rabbit serum. Input (10-20\% of the sample for immunoprecipitation) was used as a positive control. The DNA fragments were purified and identified using real-time PCR assay with the primers listed in Table 1.

\section{Luciferase Assay}

The preparation of the vectors was as described above. The luciferase assay was carried out as previously described [27, 28]. In brief, HEK293T cells were grown at $37^{\circ} \mathrm{C}$ in $5 \% \mathrm{CO}_{2}$ and $90 \%$ humidity and seeded in 12 -well plates. One day later, the cells were transfected with $40 \mathrm{ng}$ of the pRL-TK plasmid (a normalizing control; Promega, Madison, WI) alone or plus $1 \mu \mathrm{g}$ of the constructed vectors using Lipofectamine 2000 (Invitrogen) according to the manufacturer's instructions. Two days after transfection, the cells were collected in passive lysis buffer. Approximately $40 \mu \mathrm{l}$ of supernatant was used to measure the luciferase activity with the Dual-Luciferase Reporter Assay System (Promega). Independent transfection experiments were repeated three times. The relative reporter activity was calculated after normalization of the firefly activity to Renilla activity.

\section{Statistical Analysis}

For in vivo experiments, the animals were randomly distributed into different treatment groups. For in vitro experiments, the cells were evenly suspended and then randomly distributed into each well. All of the data are given as means \pm S.E.M. The data were statistically analyzed by two-tailed, paired Student's $t$ test and a one-way or two-way ANOVA with repeated measures. When ANOVA showed significant differences, pairwise comparisons between means were analyzed by the post hoc Tukey method (SigmaPlot 12.5, San Jose, CA). Significance was set at $P<0.05$.

\section{Results}

\section{CREB Is Increased in the DRG After Paclitaxel Injection}

To demonstrate the role of DRG CREB in CIPNP, we first examined CREB abundance and activation in the DRG as well as behavioral responses after systemic administration of paclitaxel. Consistent with our previous studies [7], intraperitoneal injection of paclitaxel (dissolved in vehicle 1), but not vehicle 1, produced robust and long-lasting mechanical allodynia evidenced by marked increases in paw withdrawal frequencies in response to $0.07 \mathrm{~g}$ and $0.4 \mathrm{~g}$ von Frey filaments and heat hyperalgesia demonstrated by significant decreases in paw withdrawal latencies to heat stimulation on both left and right sides (Fig. 1a-c). These pain hypersensitivities occurred on day 7 after the first paclitaxel injection and persisted for at least 21 days (Fig. 1a-c). Correlating with these behavioral changes, the expression of CREB and its activated form phosphorylated (p)-CREB was timedependently increased in the DRG after paclitaxel injection. The amount of total CREB protein in L3/4 DRGs was increased 1.5-fold $(P<0.05), 2.3$-fold $(P<0.01)$, and 1.2-fold $(P>0.05)$ on days 7,14 , and 21 after the first paclitaxel injection, respectively, as compared to naïve mice (Fig. 1d, e). Consistently, the levels of p-CREB in L3/4 DRGs were elevated by 2.1 -fold $(P<0.01), 2.9$-fold $(P<0.01)$, and 0.9 -fold $(P>0.05)$ on days 7,14 , and 21 after the first paclitaxel injection, respectively, compared with those in naïve mice (Fig. 1f, g). As expected, vehicle 1 injection did not alter basal expression of both total CREB and p-CREB in the L3/4 DRGs (Fig. 1d-g). Unexpectedly, the ratios of $\mathrm{p}-\mathrm{CREB}$ to total CREB at different time points after the first paclitaxel injection were not significantly different from those after the first vehicle 1 injection (Fig. 1h), indicating that p-CREB increase is due to the increase of total CREB. Interestingly, paclitaxel injection did not change basal expression of total CREB (Fig. 1i) and pCREB (data not shown) in the L3/4 spinal cord dorsal horn. In line with previous reports $[12,13,17]$, CREB is expressed mainly in the nuclei of DRG neurons as it predominantly coexpressed with $\beta$-tubulin III, a specific marker for neurons, in the DRG (Fig. 2a). Further, the number of CREB-positive neurons in L4 DRG on days 14 after the first paclitaxel injection was increased (Fig. 2a). Approximately 53\% (125/235) of $\beta$-tubulin III-labeled neurons were positive for CREB in the vehicle 1 -treated group, whereas about $79 \%(241 / 305)$ of $\beta$ tubulin III-labeled neurons were positive for CREB in the PTX-treated group (Fig. 2a). Distribution patterns of CREB expression in the L4 DRG on days 14 after the first paclitaxel injection were also examined. Approximately $10 \%$ of CREBlabeled neurons are small $\left(<300 \mu \mathrm{m}^{2}\right.$ in area), 52\% are medium $\left(300-600 \mu \mathrm{m}^{2}\right.$ in area), and $38 \%$ are large $\left(>600 \mu \mathrm{m}^{2}\right.$ in area) in the vehicle 1-treated group (Fig. 2b), whereas about $10 \%$ of CREB-labeled neurons are small, $65 \%$ are medium, and $25 \%$ are large in the paclitaxel-treated group (Fig. 2b). Collectively, our data indicate that CREB is dramatically upregulated in DRG neurons after paclitaxel injection, suggesting that DRG CREB likely contributes to CIPNP.

\section{Effect of DRG Microinjection of Creb siRNA on the Development of Paclitaxel-Induced Nociceptive Hypersensitivities}

To examine whether DRG CREB in the DRG participated in the development of CIPNP, we blocked the paclitaxel-induced increase in CREB through microinjection of Creb short interfering RNA (Creb siRNA; dissolved in vehicle 2) into unilateral L3/4 DRGs on day 4 after the first intraperitoneal injection of vehicle 1 or paclitaxel. Negative control scrambled 

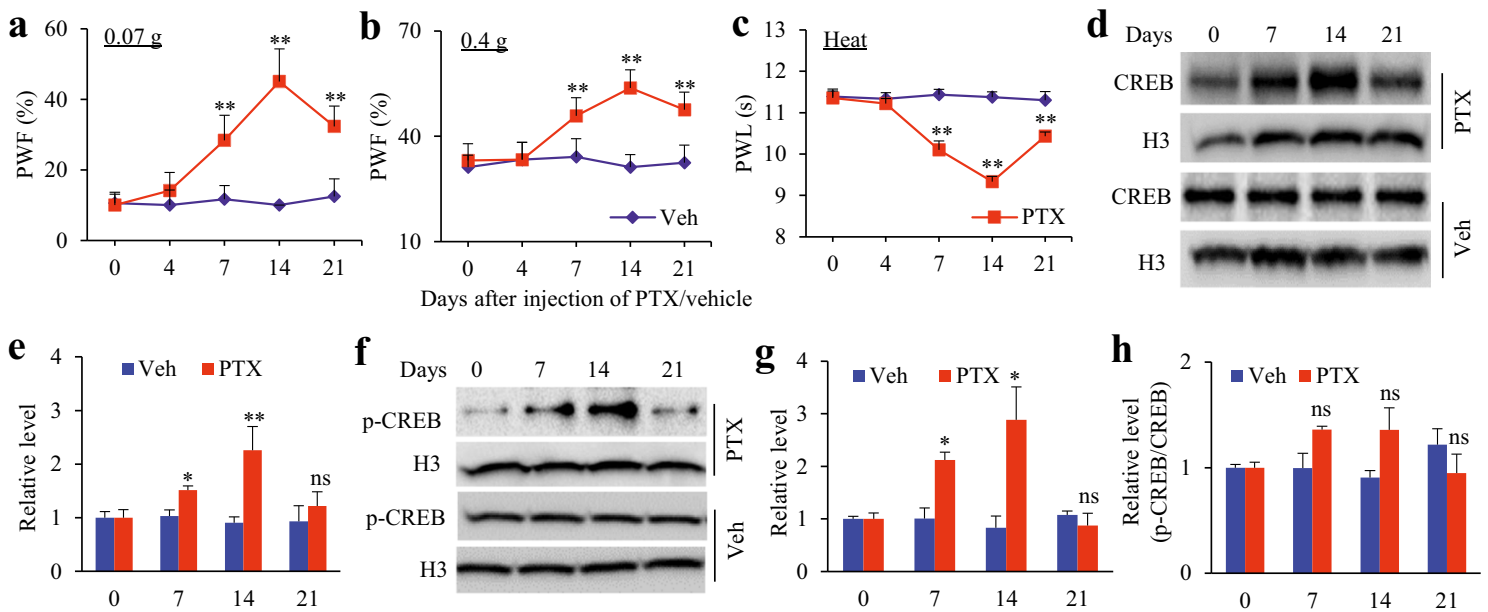

h

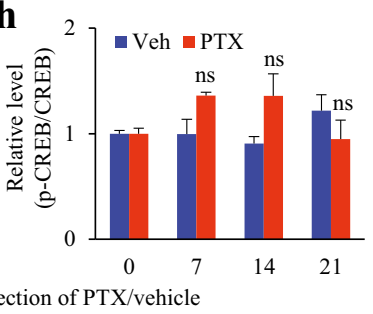

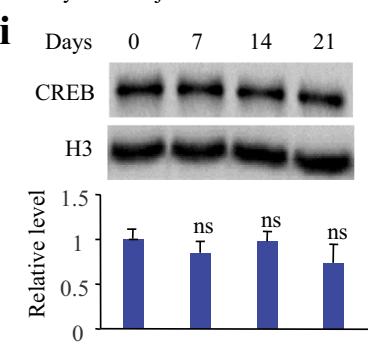

Fig. 1 CREB abundance is increased in the DRG after paclitaxel injection. PTX: paclitaxel. Veh: vehicle. $(\mathrm{a}-\mathrm{c})$ Intraperitoneal injection of paclitaxel produced mechanical allodynia as evidenced by increases in paw withdrawal frequencies (PWF) in response to $0.07 \mathrm{~g}$ (a) and $0.4 \mathrm{~g}$ (b) von Frey filaments and heat hyperalgesia as demonstrated by the decrease in paw withdrawal latency (PWL) to heat stimulation (c) on the left side. $n=10$ mice/time point. $* * P<0.01$ versus the vehicletreated group at the corresponding time points by two-way ANOVA with repeated measures followed by post hoc Tukey test. $(\mathrm{d}-\mathrm{h})$ Expression of total CREB (d, e) and p-CREB (f, g) proteins, and the ratios of p-CREB to total CREB $(\mathrm{H})$ in $\mathrm{L} 3 / 4$ DRGs on days as

siRNA (NC siRNA; dissolved in vehicle 2) was used as a control. The specificity and efficiency of $\mathrm{Creb}$ siRNA were first examined in in vitro cultured DRG neurons. Compared to the NC siRNA-treated group, Creb siRNA markedly reduced the abundance of p-CREB and CREB, but not of octamer binding factor 1 (OCT1; another transcription factor) and cJun N-terminal kinase, in cultured DRG neurons (Fig. 3a). We then examined the effect of DRG microinjection of $\mathrm{Creb}$ siRNA into unilateral L3/4 DRGs on the expression of DRG total CREB and p-CREB on day 9 after the first vehicle 1 or paclitaxel injection. As expected, the levels of total CREB and p-CREB in the injected L3/4 DRGs were increased by 2.3fold and 2.9-fold, respectively, in the paclitaxel plus vehicle 2-treated group as compared with those in the vehicle 1-plus vehicle 2-treated group (Fig. 3b). These increases were not seen in the paclitaxel plus Creb siRNA-treated group (Fig. 3b). Basal levels of total CREB and p-CREB were not significantly changed in the injected L3/4 DRG of the Creb siRNA plus vehicle 1-treated group (Fig. 3b). Microinjection of NC siRNA did not affect the paclitaxel injection-induced indicated after first injection of paclitaxel or vehicle. Representative Western blot images $(\mathrm{d}, \mathrm{f})$ and summary of densitometric analyses (e, g, h) are shown. $n=4$ biological replicates $(8$ mice)/time point. $* P<0.05$, $* * P<0.01$ versus the corresponding control group (day 0 ) by two-way ANOVA with repeated measures followed by post hoc Tukey test. ns: no statistical significance versus the corresponding control group. (i) CREB protein expression in the L3/4 spinal cord dorsal horn on days as shown after first injection of paclitaxel or vehicle. $n=4$ biological replicates $(8$ mice)/time point. ns: no statistical significance versus the corresponding control group. One-way ANOVA with repeated measures followed by post hoc Tukey test

increases in the amounts of both total CREB and p-CREB in the injected L3/4 DRGs (Fig. 3b). As expected, the ratios of pCREB to total CREB were not marked different among the treated groups (Fig. 3c).

We further investigated whether DRG microinjection of Creb siRNA affected the development of paclitaxel-induced nociceptive hypersensitivities. Compared to the vehicle $1-$ plus vehicle 2-treated group, paw withdrawal frequencies to $0.07 \mathrm{~g}$ and $0.4 \mathrm{~g}$ von Frey filament stimuli were significantly increased and paw withdrawal latencies to heat and cold stimuli were markedly reduced on days 7 and 9 after the first paclitaxel injection on both ipsilateral (Fig. 3d-g) and contralateral (Fig. 3h-j) sides of the vehicle 2-microinjected mice. However, the mice microinjected with Creb siRNA exhibited the attenuation of the increased paw withdrawal frequencies to $0.07 \mathrm{~g}$ and $0.4 \mathrm{~g}$ von Frey filament stimuli and of the reduced paw withdrawal latencies to heat and cold stimuli on the ipsilateral (Fig. 3d-g), but not contralateral (Fig. 3h-j), side on days 7 and 9 after the first paclitaxel injection. As expected, these effects were not observed in the mice microinjected with 

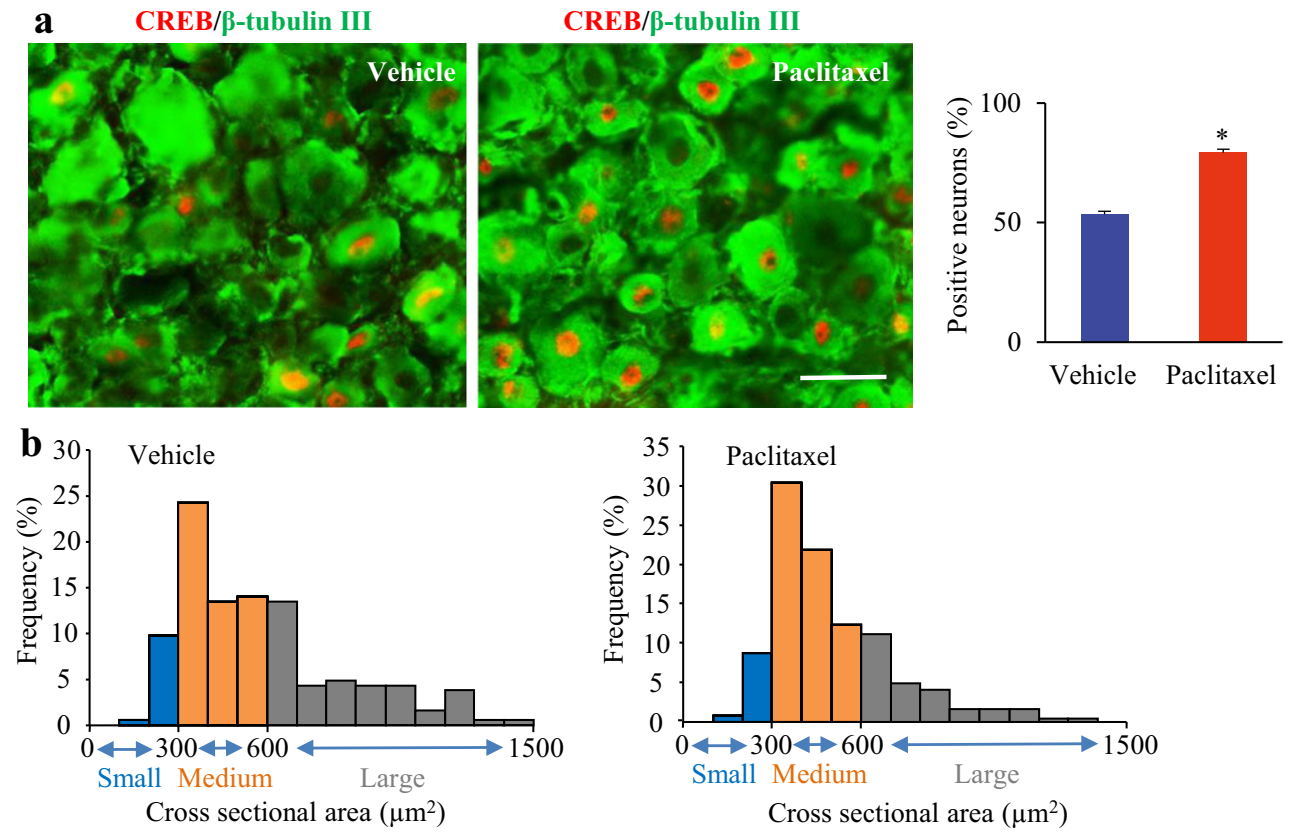

Fig. 2 Effect of intraperitoneal injection of paclitaxel or vehicle on number of CREB-labeled neurons and their distribution patterns in the DRG. (a) Number of CREB-labeled neurons in L4 DRG on day 14 after first injection of paclitaxel or vehicle 1. Left panels: representative immunofluorescent staining for CREB (red) and $\beta$-tubulin III (green). Right graph: summary of the number of CREB-labeled neurons. $n=5$

NC siRNA (Fig. 3d-j). Neither siRNA affected locomotor functions (Table 2) or basal paw withdrawal responses to mechanical, heat, and cold stimuli on the ipsilateral and contralateral sides of the vehicle 1-injected mice during the observation period (Fig. 3d-j).

\section{Effect of DRG Microinjection of Creb siRNA on Established Nociceptive Hypersensitivities After Paclitaxel Injection}

To further examine the role of DRG CREB in established nociceptive hypersensitivities following paclitaxel injection, we microinjected siRNA into unilateral L3/4 DRGs on day 7 post-paclitaxel injection. At this time point, mechanical allodynia, heat hyperalgesia, and cold hyperalgesia were robustly developed on both sides (Fig. 4a-g). DRG microinjection of $\mathrm{Creb}$ siRNA attenuated paclitaxel-induced increases in paw withdrawal frequencies to $0.07 \mathrm{~g}$ and $0.4 \mathrm{~g}$ von Frey filament stimuli and reductions in paw withdrawal latencies to heat and cold stimuli on days 10 and 12 after the first paclitaxel injection on the ipsilateral (Fig. 4a-d), but not contralateral (Fig. $4 \mathrm{e}-\mathrm{g}$ ), side, as compared with those on day 7 post-paclitaxel injection. In contrast, in the NC siRNAmicroinjected mice, paclitaxel-induced increases in paw withdrawal frequencies to $0.07 \mathrm{~g}$ and $0.4 \mathrm{~g}$ von Frey filament stimuli and reductions in paw withdrawal latencies to heat and cold stimuli were still seen on days 10 and 12 post-

mice (10 DRGs)/group. $* P<0.05$ versus the vehicle 1 -treated group by two-tailed, independent Student's $t$ test. Scale bar, $50 \mu \mathrm{m}$. (b) Histogram shows the distribution of CREB-positive somata in L4 DRG on day 14 after first injection of paclitaxel or vehicle 1. Vehicle 1-treated group: small, 10\%; medium, 52\%; large, 38\%. Paclitaxel-treated group: small, $10 \%$, medium, $65 \%$; large, $25 \%$

paclitaxel injection on both ipsilateral and contralateral sides (Fig. 4a-g).

\section{DRG Overexpression of CREB Leads to Nociceptive Hypersensitivity}

To determine whether increased DRG CREB was sufficient for CIPNP, we microinjected AAV5 that expressed full-length Creb protein (AAV5-CREB) into unilateral L3/4 DRGs of naïve adult mice. AAV5 expressing enhanced green fluorescent protein (AAV5-EGFP) was used as a control. In line with our expectation, significant increases in the levels of total CREB and p-CREB were seen in the injected DRGs 8 weeks after microinjection of AAV5-CREB compared with microinjection of AAV5-EGFP (Fig. 5a, b). The ratios of p-CREB to total CREB among the treated groups were similar (Fig. 5c). Mice microinjected with AAV5-CREB, but not AAV5EGFP, exhibited robust increases in paw withdrawal frequencies in response to $0.07 \mathrm{~g}$ and $0.4 \mathrm{~g}$ von Frey filament stimuli (Fig. 5d, e) and significant decreases in paw withdrawal latencies in response to heat and cold stimuli (Fig. 5f, g) on the ipsilateral side. These nociceptive hypersensitivities occurred 4 weeks post-microinjection and persisted for at least 8 weeks (Fig. 5d-g), consistent with the 3-4-week lag period of AAV5 expression, which lasts for at least 3 months [27, 30, 31]. Neither virus affected locomotor function (Table 2) or basal contralateral paw withdrawal responses (Fig. 5d-g). 

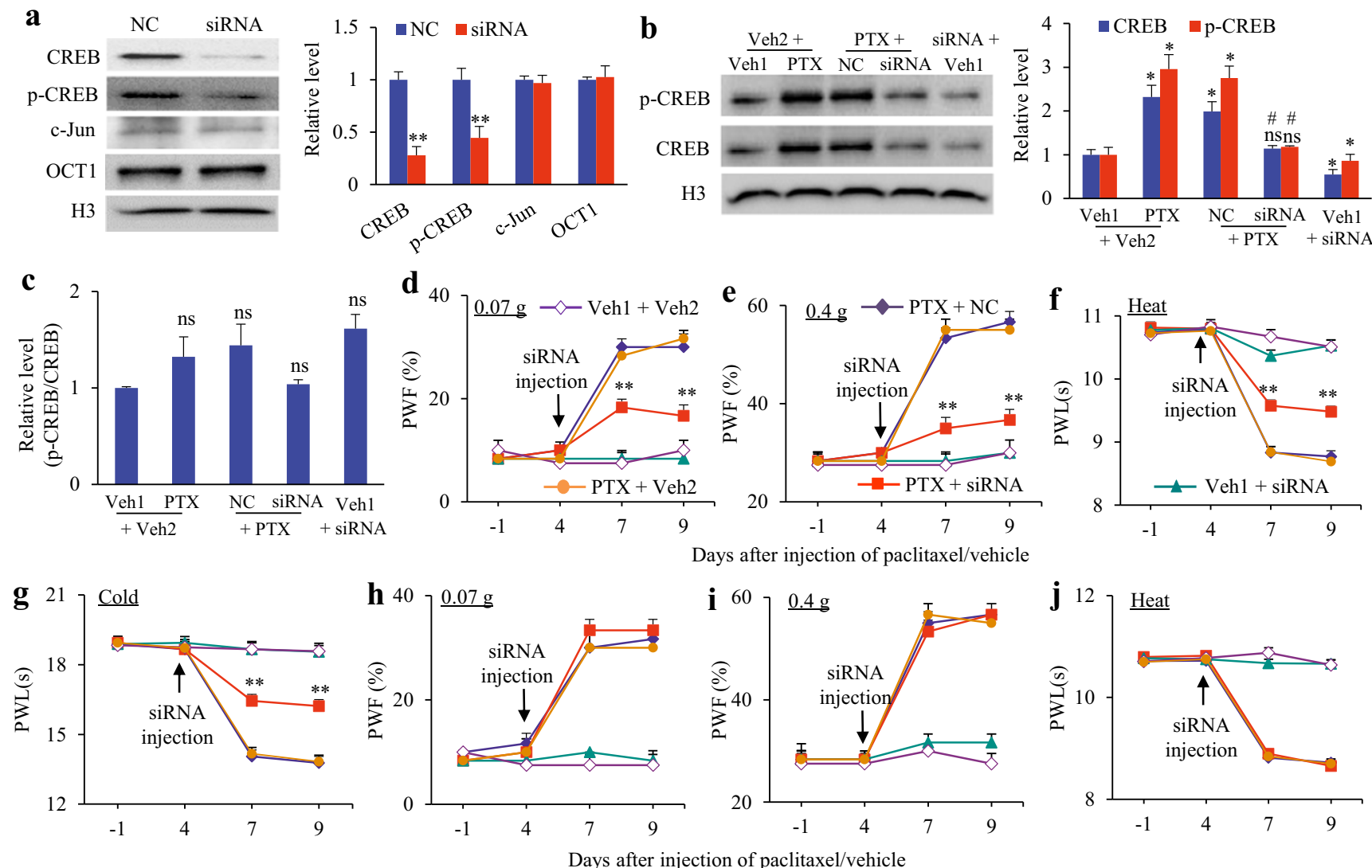

Fig. 3 Effect of blocking paclitaxel-induced increase in DRG CREB protein on paclitaxel-induced development of nociceptive hypersensitivities. siRNA: Creb siRNA. NC: negative control siRNA. PTX: paclitaxel. (a) Expression of CREB, p-CREB, c-Jun, and OCT1 in cultured DRG neurons after transfection of negative control siRNA or Creb siRNA. Representative Western blots (left) and a summary of the densitometric analyses (right) are shown. $n=3$ biological replicates per treatment. $* * P<0.01$ versus the corresponding negative control siRNA (NC) group by two-tailed, independent Student's $t$ test. (b, c) Expression of total CREB and p-CREB protein (b) and the ratios of pCREB to total CREB (c) in the ipsilateral L3/4 DRGs on day 9 after first injection of paclitaxel or vehicle 1 (Veh1) in mice with treatments of vehicle 2 (Veh2) or siRNA as indicated. (b) Representative Western blots (left) and a summary of the densitometric analyses (right) are

Furthermore, the CPP test showed that mice microinjected with AAV5-CREB (but not AAV5-EGFP) spent more time

Table 2 Locomotor function

\begin{tabular}{llll}
\hline Treatment groups & Placing & Grasping & Righting \\
\hline Vehicle 1 + vehicle 2 & $5(0)$ & $5(0)$ & $5(0)$ \\
Paclitaxel + vehicle 2 & $5(0)$ & $5(0)$ & $5(0)$ \\
Paclitaxel + NC siRNA & $5(0)$ & $5(0)$ & $5(0)$ \\
Paclitaxel + Creb siRNA & $5(0)$ & $5(0)$ & $5(0)$ \\
Vehicle1 + Creb siRNA & $5(0)$ & $5(0)$ & $5(0)$ \\
AAV5-EGFP & $5(0)$ & $5(0)$ & $5(0)$ \\
AAV5-CREB & $5(0)$ & $5(0)$ & $5(0)$ \\
\hline
\end{tabular}

$n=8-12$ mice per group; five trials; mean (SEM) shown. $n=6-8$ mice per group. $* P<0.01$ versus the corresponding Veh1 plus Veh2 group. ${ }^{\#} P<0.01$ versus the corresponding Veh2 plus PTX group. ns: no statistical significance versus the Veh1 plus Veh2 group. One-way ANOVA with repeated measures followed by post hoc Tukey test. (d-j) Microinjection of vehicle 2, negative control siRNA or Creb siRNA into the unilateral L3/4 DRGs was carried out 4 days after intraperitoneal injection of paclitaxel or vehicle (Veh1). Paw withdrawal responses to $0.07 \mathrm{~g}$ von Frey filament $(\mathrm{d}, \mathrm{h}), 0.4 \mathrm{~g}$ von Frey filament (e, i), heat $(f, j)$ and cold $(g)$ stimuli on the ipsilateral $(\mathrm{d}-\mathrm{g})$ and contralateral $(\mathrm{h}-$ j) sides from the treated groups as indicated on days after first injection of paclitaxel or vehicle. $n=8$ mice/group. $* * P<0.01$ versus the PTX plus Veh2 group at the corresponding time points by two-way ANOVA with repeated measures followed by post hoc Tukey test

in the lidocaine-paired chamber (Fig. 5h, i), indicating stimulation-independent spontaneous pain. The results revealed that increased DRG CREB leads to both spontaneous and evoked nociceptive hypersensitivities, symptoms of CIPNP commonly seen in the clinic.

\section{CREB Transcriptionally Activates Dnmt3a Expression in the DRG Following Paclitaxel Injection}

Finally, we investigated the mechanism by which CREB, acting as a transcription factor in the DRG, contributes CIPNP. Prediction by TFSEARCH software analysis indicated a consensus CREB-binding motif (-205/aacggtgacgcc/-194) in the promoter region of the Dnmt3a gene. Given that paclitaxel injection-induced increases in Dnmt3a mRNA and its coded 

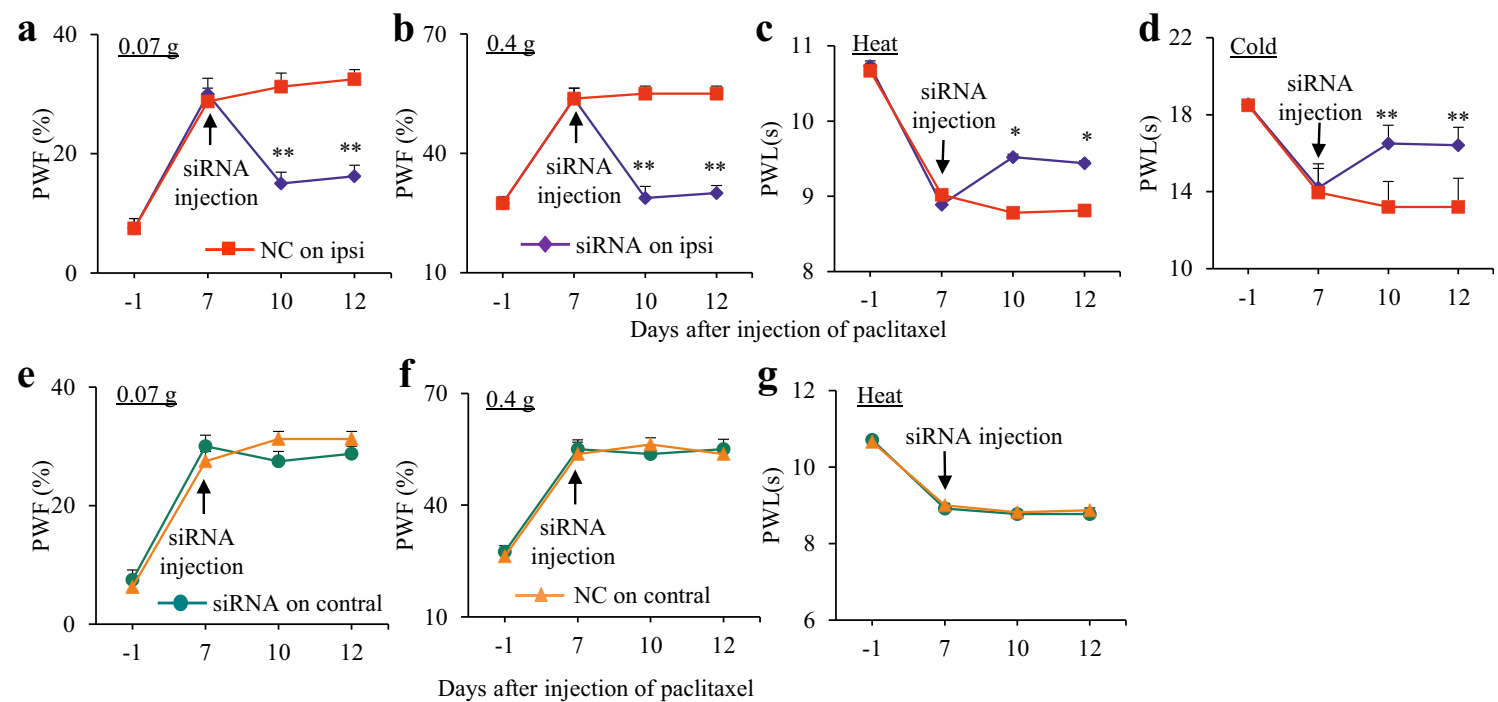

Fig. 4 Effect of blocking paclitaxel-induced increase in DRG CREB protein on established nociceptive hypersensitivities caused by paclitaxel injection. siRNA: Creb siRNA. NC: negative control siRNA. Veh: vehicle. PTX: paclitaxel. Microinjection of negative control siRNA or Creb siRNA into the unilateral L3/4 DRGs was carried out 7 days after the first intraperitoneal injection of paclitaxel or vehicle. Paw withdrawal responses to $0.07 \mathrm{~g}$ von Frey filament (a, e), $0.4 \mathrm{~g}$ von Frey filament (b, f),

protein in the DRGs are required for CIPNP [7], we assumed that CREB participated in paclitaxel-induced CIPNP by transcriptionally activating the Dnmt $3 a$ gene in the DRGs. Indeed, chromatin immunoprecipitation (ChIP) assays revealed that a Dnmt3a promoter fragment including the above binding motif was amplified from the complex immunoprecipitated with a rabbit anti-CREB antibody in the nuclear fractions of DRGs on day 14 after the first vehicle 1 injection (Fig. 6a). This amplification did not occur with control normal rabbit serum (Fig. 6a) or after pre-absorption of Runx1 antibody (data not shown), suggesting specific binding of CREB to the Dnmt3a promotor in DRGs. Paclitaxel injection produced a significant increase in binding activity between CREB and the Dnmt3a gene promoter as demonstrated by a 2.7 -fold increase in band density in DRGs on day 14 after the first paclitaxel injection compared to the vehicle 1-treated group (Fig. 6a). To further examine whether CREB directly activated Dnmt $3 a$ gene transcriptional activity, we carried out luciferase assay on transfected human embryonic kidney (HEK)-293T cells. Cotransfection of reporter vector (containing the Dnmt3a promoter fragment) with CREB vector (encoding full-length CREB), but not with control EGFP vector, significantly increased the activity of the Dnmt3a gene promoter including the CREB-binding motif (Fig. 6b). We further confirmed the CREB-triggered increase in DNMT3a expression in cultured DRG neurons that were transduced with AAV5-CREB, but not with AAV5-EGFP (Fig. 6c). This increase was attenuated in the cultured neurons by co-treatment with $\mathrm{Creb}$ siRNA, but not with NC siRNA (Fig. 6c), suggesting that the induction of DNMT3a was specifically in response to CREB. Cultured

heat (c, g), and cold (d) stimuli on the ipsilateral (a-d) and contralateral $(\mathrm{e}-\mathrm{g})$ sides from the treated groups as indicated on days after first injection of paclitaxel or vehicle. $n=8$ mice/group. $* P<0.05$ or $* * P<$ 0.01 versus the PTX plus NC group at the corresponding time points by two-way ANOVA with repeated measures followed by post hoc Tukey test

DRG neurons treated with Creb siRNA plus AAV5-EGFP exhibited markedly reduced basal levels of CREB and DNMT3a (Fig. 6c).

Furthermore, DRG microinjection of Creb siRNA, but not of NC siRNA, significantly blocked the paclitaxel-induced increase in the level of DNMT3a in the injected DRGs on day 9 after first paclitaxel injection (Fig. 7a). Basal amount of DNMT3a protein was not markedly altered in the $\mathrm{Creb}$ siRNA-injected DRG on day 9 after the first vehicle 1 injection (Fig. 7a). Consistently, DRG microinjection of AAV5CREB, but not of AAV5-EGFP, into the unilateral L3/4 DRGs increased the amounts of DNMT3a protein in the injected DRGs 8 weeks after viral microinjection (Fig. 7b). Additionally, double immunofluorescence staining showed that approximately $85 \%(1060 / 1242)$ of the CREB-labeled DRG neurons were positive for DNMT3a and that about $86 \%(1060 / 1235)$ of DNMT3a-labeled DRG neurons were positive for CREB (Fig. 7c). Taken together, our findings suggest that CREB participates in the paclitaxel-induced upregulation of DRG DNMT3a.

\section{Discussion}

Paclitaxel injection-induced peripheral nociceptive hypersensitivities in mice may mimic neuropathic pain caused by chemotherapy drugs in the clinic. Investigating the mechanism by which paclitaxel injection produces nociceptive hypersensitivities may open up new avenues for CIPNP management. In the present study, we for the first time showed the 

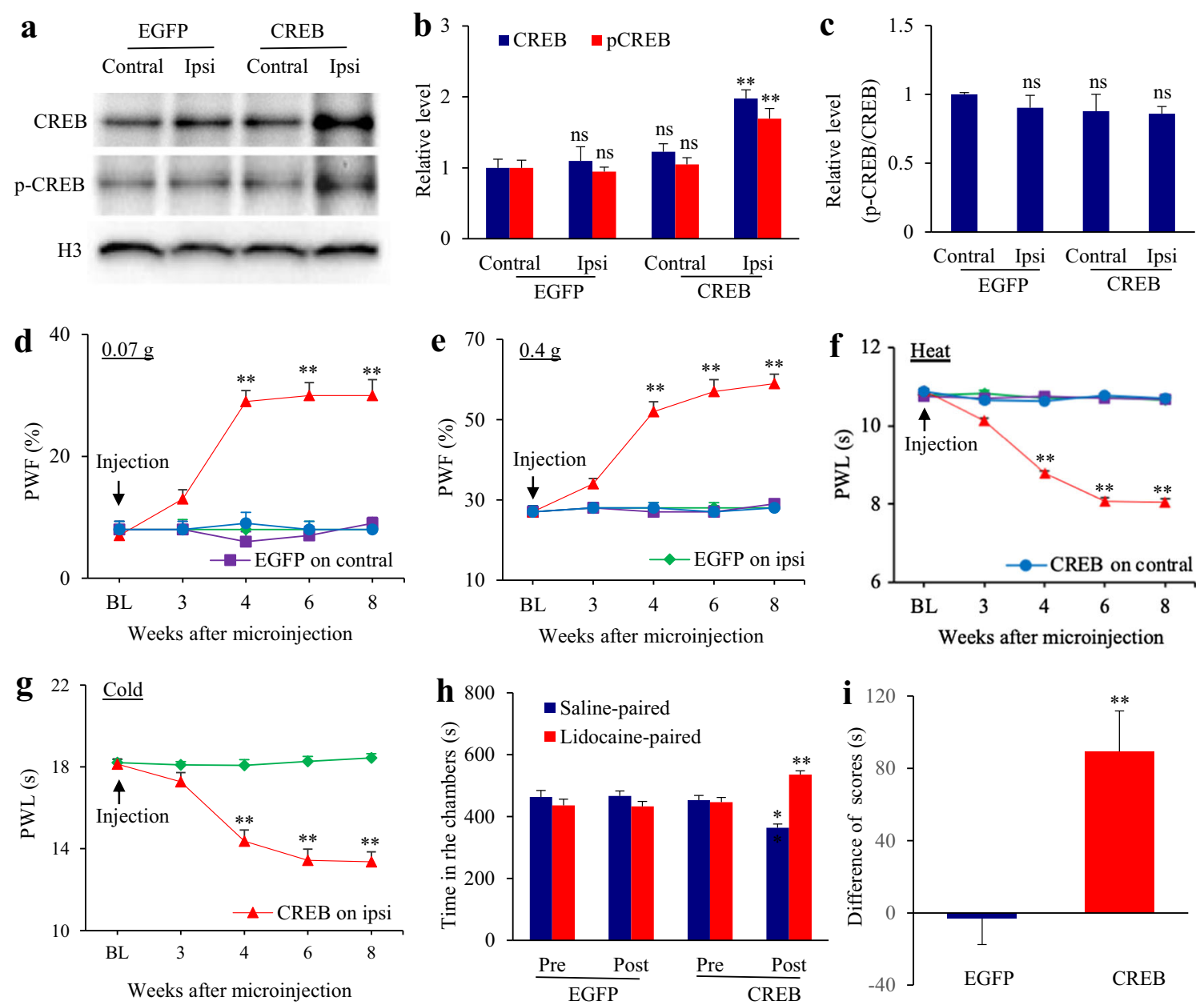

Fig. 5 Effect of DRG CREB overexpression on nociceptive thresholds in naïve mice. Contral: contralateral. Ipsi: Ipsilateral. EGFP: AAV5-EGFP. CREB: AAV5-CREB. (a-c) The levels of total CREB and p-CREB proteins $(a, b)$ and the ratios of p-CREB to total CREB (c) in the ipsilateral L3/4 DRGs 8 weeks after microinjection of AAV5-CREB or control AAV5-EGFP. Representative Western blots (a) and a summary of the densitometric analyses (b) are shown. $n=3$ biological repeats $(6$ mice)/group. $* * P<0.01$ versus the corresponding AAV5-EGFP group on the contralateral side by one-way ANOVA with repeated measures followed by post hoc Tukey test. ns: no statistical significance versus the corresponding AAV5-EGFP group on the contralateral side. (d-g) Paw withdrawal responses to $0.07 \mathrm{~g}$ von Frey filament (d), $0.4 \mathrm{~g}$ von Frey filament (e), heat (f), and cold (g) stimuli on the ipsilateral and contralateral sides from the treated groups as indicated on weeks after microinjection of AAV5-CREB or AAV5-EGFP into the unilateral L3/4 DRGs. $n=10$ mice/group. $* * P<0.01$ versus the control AAV5-EGFP group on the contralateral side at the corresponding time points by twoway ANOVA with repeated measures followed by post hoc Tukey test. (h, i) Paclitaxel injection-induced spontaneous ongoing pain by adopting conditional place preference paradigm 7 weeks after microinjection of AAV5-CREB or AAV5-EGFP into the unilateral L3/4 DRGs. Pre: preconditioning. Post: post-conditioning. $n=10$ mice/group. $* * P<0.01$ versus the corresponding preconditioning by two-way ANOVA with repeated measures followed by post hoc Tukey test (h) or the AAV5EGFP group by two-tailed, independent Student's $t$ test (i)

CREB may contribute to CIPNP likely through transcriptional activation of Dnmt3a in the DRG.

CREB is widely expressed throughout the brain, spinal cord, and DRG [36]. Like other transcription factors such as myeloid zinc finger 1, CCAAT/enhancer binding protein $\beta$, and OCT1 [28-30, 32], CREB may be upregulated in painprocessing regions under neuropathic pain conditions. The expression of p-CREB in the DRG and spinal cord dorsal horn neurons was significantly increased in a rat model of type II diabetic neuropathic pain [15]. Sciatic nerve transection increased CREB immunoreactivity in glial cells of both spinal Dnmt3a gene promoter after paclitaxel exposure. Therefore, 

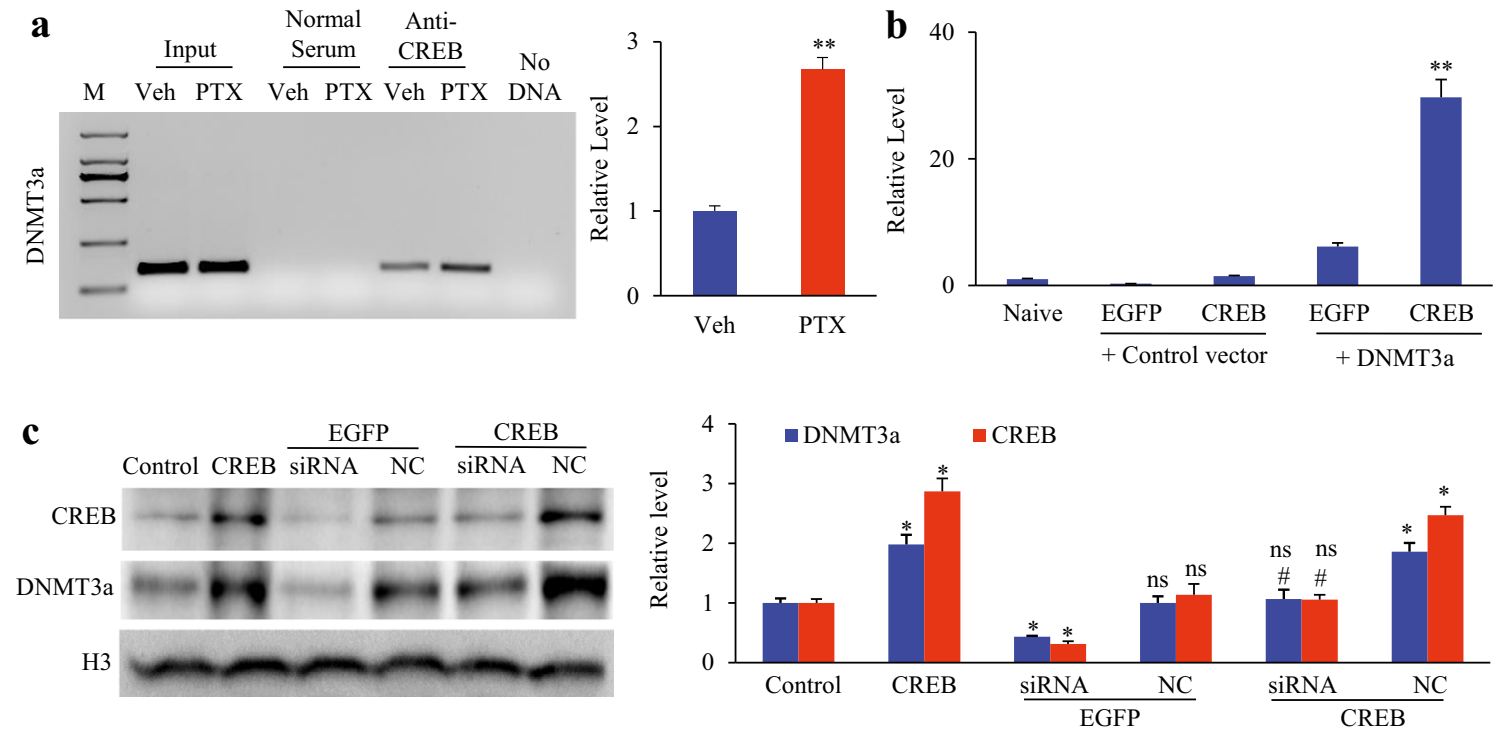

Fig. 6 CREB transcriptionally activates Dnmt3a expression in DRG neurons. (a) The Dnmt3a promoter fragment immunoprecipitated with rabbit anti-CREB antibody in the ipsilateral L3/4 DRG on day 14 after first injection of paclitaxel (PTX) or vehicle (Veh). Left: representative binding of CREB to Dnmt3a promoter. Right: quantitative analysis of the binding. Input, total purified fragments. M, ladder. $n=3$ biological repeats $(9$ mice)/group. $* * P<0.01$ versus the vehicle group by twotailed, independent Student's $t$ test. (b) Dnmt3a gene promoter activity in HEK-293T cells transfected/transduced with or without the vectors plus AAV5 as shown. Control vector: control empty pGL3-Basic. DNMT3a: pGL3-Dnmt3a vector. EGFP: AAV5-EGFP. CREB: AAV5-

cord dorsal and ventral horns [37]. In the present study, we found that paclitaxel injection time-dependently increased the level of total CREB in DRGs, but not in the spinal cord. This increase occurred on day 7 after the first paclitaxel injection, persisted for at least 1 week and returned to basal levels by day 21 after the first paclitaxel injection. These data indicate that paclitaxel-induced CREB increase is time-dependent and DRG-specific and participates in paclitaxel-induced pain hypersensitivity at the early (not late) phase. The increase in the activated form $\mathrm{p}$-CREB observed in the present study is attributed to total CREB increase. The mechanism by which paclitaxel upregulates CREB expression remains unclear, but this upregulation may be related to epigenetic modifications, posttranslational modifications, and increases in RNA stability following paclitaxel injection. These possibilities merit further investigation in future studies. In addition, as CREB has been identified as a downstream factor of extracellular signalregulated kinase 1/2, Ca2+/calmodulin-dependent protein kinase II, or mitogen-activated protein kinase pathways [19, 20], participation of these kinases in the paclitaxel-induced DRG CREB upregulation could not be ruled out.

To investigate the role of DRG CREB in paclitaxelinduced neuropathic pain, we carried out the siRNA strategy to block the paclitaxel-induced increase of DRG CREB expression. Our in vitro experiments showed that $\mathrm{Creb}$ siRNA knocked down basal expression of CREB without altering
CREB. $n=3$ biological repeats/treatment. $* * P<0.01$ versus naïve group by one-way ANOVA with repeated measures followed by post hoc Tukey test. (C). Levels of CREB and DNMT3a proteins in the cultured DRG neurons transfected/transduced with or without siRNA plus AAV5 as shown. Control: naïve group. EGFP: AAV5-EGFP. CREB: AAV5CREB. NC: negative control siRNA. siRNA: Creb siRNA. $N=5$ biological repeats/treatment. $* * P<0.01$ versus control naïve group. ${ }^{\# \#} P<0.01$ versus the AAV5-CREB-transduced group. ns: no statistical significance versus the corresponding control group. One-way ANOVA with repeated measures followed by post hoc Tukey test

basal expression of c-Jun and OCT1 proteins in cultured DRG neurons, indicating the specificity and selectivity of Creb siRNA targeting. Our in vivo study revealed that DRG microinjection of $\mathrm{Creb}$ siRNA, but not negative control siRNA, blocked the paclitaxel-induced increase in DRG CREB expression and nociceptive hypersensitivities during the development and establishment periods. Locomotor activities remained normal in all microinjected mice. These findings further suggest the specificity and selectivity of $\mathrm{Creb}$ siRNA effects. Unexpectedly, DRG microinjection of $\mathrm{Creb}$ siRNA did not markedly alter basal expression of CREB in injected DRG of the vehicle 1-treated mice, although it significantly reduced basal level of CREB in the cultured DRG neurons. The mechanism by which $\mathrm{Creb}$ siRNA did not affect basal CREB expression in vivo is unknown but could be due to its low expression in the DRG under normal conditions. The Creb siRNA cannot further produce a significant CREB reduction at the basal level. Additionally, the remaining $\mathrm{Creb}$ mRNA after its knockdown may have a high translational efficacy, which likely maintains normal level of basal CREB protein in the vehicle 1-treated DRG.

The increased DRG CREB may participate in paclitaxelinduced nociceptive hypersensitivities by triggering $D n m t 3 a$ gene transcription in the injured DRG. DNMT3a-triggered DNA methylation, a type of epigenetic modification, represses gene expression [38-40]. We recently reported that 

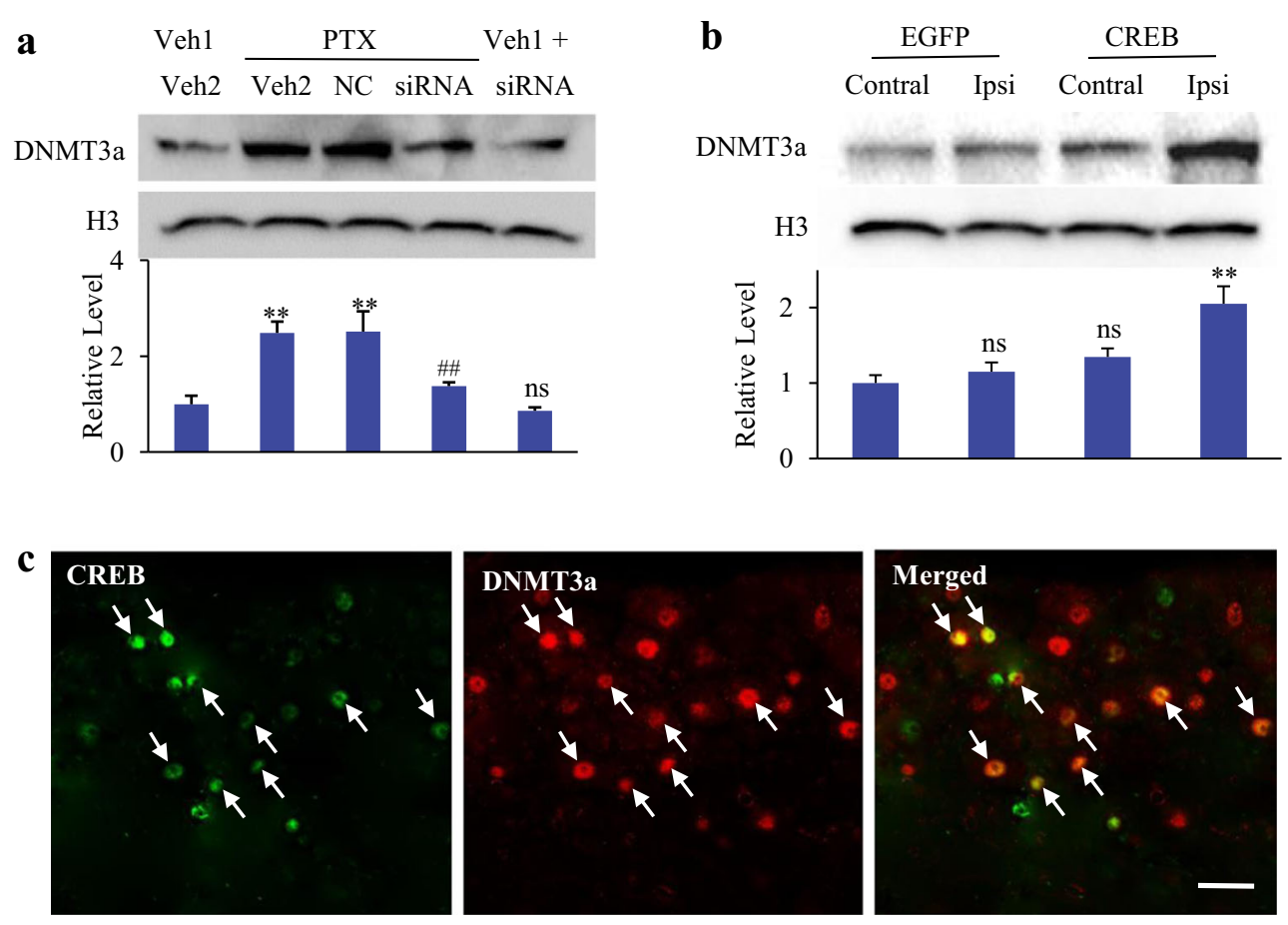

Fig. 7 CREB participates in paclitaxel injection-induced increase in DNMT3a in DRG neurons. (a) Level of DNMT3a protein in the microinjected L3/4 DRGs on day 7 after first injection of paclitaxel (PTX) or vehicle 1 (Veh1) in mice microinjected with vehicle 2 (Veh2), negative control siRNA (NC), or CREB siRNA (siRNA) into the unilateral L3/4 DRGs. $n=3$ biological repeats (6 mice)/group. $* * P<$ 0.01 versus the corresponding Veh1 plus Veh2 group. ${ }^{\#} P<0.01$ versus the Veh2 plus PTX group. One-way ANOVA with repeated measures followed by post hoc Tukey test. ns: no statistical significance versus the Veh1 plus Veh2 group. (b) Level of DNMT3 protein in the microinjected

L3/4 DRGs on the ipsilateral (Ipsi) and contralateral (Contral) sides 8 weeks after microinjection of AAV5-CREB (CREB) or AAV5-EGFP (EGFP). $n=3$ biological repeats ( 6 mice)/group. $* * P<0.01$ versus the AAV5-EGFP group on the contralateral side by one-way ANOVA with repeated measures followed by post hoc Tukey test. ns: no statistical significance versus the AAV5-EGFP group on the contralateral side. (c) Representative images showed co-expression of CREB (green) with DNMT3a (red) in mouse DRG neurons (arrows). $n=3$ biological repeats from 3 mice. Scale bar, $50 \mu \mathrm{m}$

paclitaxel injection increased the expression of DNMT3a in DRG neurons [7]. Pharmacological inhibition or DRG knockout of DNMT3a significantly attenuated paclitaxel-induced nociceptive hypersensitivities [7]. These effects were mediated by a decrease in DNMT3a-triggered methylation of the $K_{2 p} 1.1$ gene promoter, subsequent rescue of DRG $\mathrm{K}_{2 \mathrm{p}} 1.1$ downregulation, and inhibition of the increased excitability in DRG neurons [7]. In addition to $\mathrm{K}_{2 \mathrm{p}} 1.1$, DNMT3a binds to the Kcan 2 gene promoter and participates in nerve injuryinduced downregulation of Kcna2 mRNA in the injured DRG [27]. DNMT3a is thus likely an endogenous instigator of paclitaxel-induced neuropathic pain genesis. The present study demonstrated that CREB was required for the paclitaxel-induced transcriptional activation of the DRG Dnmt3a gene in the DRG. Moreover, CREB co-expresses with DNMT3a and directly binds to and activates the Dnmt3a gene promoter in individual DRG neurons. Therefore, the anti-nociceptive effect produced by blocking the paclitaxel-caused increase in DRG CREB likely results from a failure to transcriptionally activate the $D n m t 3 a$ gene in the DRG. It should be noted that CREB as a transcription factor may also transcriptionally activate the expression of other genes (e.g., brain-derived neurotrophic factor [41] and fragile X mental retardation protein [42]) in the DRG after paclitaxel injection. How these genes contribute to the role of DRG CREB in CIPNP remains to be further investigated.

Other CREB-independent mechanisms may also contribute to paclitaxel-induced increase in DRG DNMT3a. We previously reported that spinal nerve ligation-caused reduction of miR-143 participated in spinal nerve ligation-induced increases in DRG Dnmt3a mRNA and DNMT3a protein as rescuing DRG miR-143 reduction attenuated these increases and impaired neuropathic pain [24]. miR-143 is thus likely a negative modulator in DRG Dnmt3a gene expression following peripheral nerve injury. In addition, like CREB, OCT1 also transcriptionally activated $D n m t 3 a$ gene promoter activity, leading to an increase in DNMT3a protein in injured DRG after chronic constriction injury [32]. Whether and how these mechanisms cooperate to modulate Dnmt3a gene expression under CIPNP conditions merits further study.

In conclusion, we demonstrated a novel CREB-triggered transcriptional mechanism of DRG DNMT3a upregulation after systemic administration of paclitaxel. Given that blocking the increased DRG CREB alleviated CIPNP without 
altering basal or acute nociceptive responses or locomotor functions, DRG CREB may be a potential target for the management of CIPNP. It should be noted that CREB is expressed in other tissues in addition to the DRG and may target other genes besides Dnmt3a. The potential side effects caused by CREB knockdown/out or inhibition need to be considered when developing future therapeutic models. However, given that PTX increased CREB expression exclusively in the injured DRG, CREB inhibition/knockdown at appropriate dosage (that only blocks the increased CREB activity without affecting basal activity) may not produce adverse effects. Additionally, DRG local or intrathecal administration of the CREB inhibitor/shRNA (delivered by virus) may also prevent side effects, given that virus-mediated gene therapy has been used in clinical trial $[43,44]$.

Acknowledgments This work was supported by grants (R01NS094664, R01NS094224, R01NS111553 and RFNS113881) from the National Institutes of Health (Bethesda, Maryland, USA).

Required Author Forms Disclosure forms provided by the authors are available with the online version of this article.

Authors' Contributions Y.X.T. conceived the project and supervised all experiments. Y.Y., J.W., B.Z., and Y.X.T. designed the project. Y.Y., Q.M., L.L., and B.Z. performed the animal model, conducted behavioral experiments, and carried out microinjection and DRG culture. J.W. and S.W. carried out Western blot, plasmid construction, DRG culture, immunohistochemistry, chromatin immunoprecipitation, and PCR experiments. Y.Y., J.W., B.Z., and Y.X.T. analyzed the data. Y.Y., J.W., B.Z., and Y.X.T. wrote the manuscript. All of the authors read and discussed the manuscript

\section{Compliance with Ethical Standards}

Conflict of Interest The authors declare that they have no competing interests.

\section{References}

1. Flatters SJL, Dougherty PM, Colvin LA (2017) Clinical and preclinical perspectives on Chemotherapy-Induced Peripheral Neuropathy (CIPN): a narrative review. Br J Anaesth 119: 737749. S0007-0912(17)53816-7 [pii];https://doi.org/10.1093/bja/ aex229 [doi].

2. Li Y, Tatsui CE, Rhines LD, North RY, Harrison DS, Cassidy RM, Johansson CA, Kosturakis AK, Edwards DD, Zhang H, Dougherty PM (2017) Dorsal root ganglion neurons become hyperexcitable and increase expression of voltage-gated T-type calcium channels (Cav3.2) in paclitaxel-induced peripheral neuropathy. Pain 158: 417-429. https://doi.org/10.1097/j.pain.0000000000000774 [doi].

3. Li Y, North RY, Rhines LD, Tatsui CE, Rao G, Edwards DD, Cassidy RM, Harrison DS, Johansson CA, Zhang H, Dougherty PM (2018) DRG Voltage-Gated Sodium Channel 1.7 Is Upregulated in Paclitaxel-Induced Neuropathy in Rats and in Humans with Neuropathic Pain. J Neurosci 38: 1124-1136. JNEUROSCI.0899-17.2017 [pii];https://doi.org/10.1523/ JNEUROSCI.0899-17.2017 [doi].
4. Sisignano M, Angioni C, Park CK, Meyer Dos SS, Jordan H, Kuzikov M, Liu D, Zinn S, Hohman SW, Schreiber Y, Zimmer B, Schmidt M, Lu R, Suo J, Zhang DD, Schafer SM, Hofmann M, Yekkirala AS, de BN, Parnham MJ, Woolf CJ, Ji RR, Scholich K, Geisslinger G (2016) Targeting CYP2J to reduce paclitaxelinduced peripheral neuropathic pain. Proc Natl Acad Sci U S A 113: 12544-12549. 1613246113 [pii];https://doi.org/10.1073/ pnas. 1613246113 [doi].

5. Zhang H, Dougherty PM (2014) Enhanced excitability of primary sensory neurons and altered gene expression of neuronal ion channels in dorsal root ganglion in paclitaxel-induced peripheral neuropathy. Anesthesiology 120: 1463-1475. https://doi.org/10.1097/ ALN.0000000000000176 [doi].

6. Mao Q, Yuan J, Ming X, Wu S, Chen L, Bekker A, Yang T, Tao YX (2017) Role of dorsal root ganglion K2p1.1 in peripheral nerve injury-induced neuropathic pain. Mol Pain 13: 1744806917701135. https://doi.org/10.1177/1744806917701135 [doi].

7. Mao Q, Wu S, Gu X, Du S, Mo K, Sun L, Cao J, Bekker A, Chen L, Tao YX (2019) DNMT3a-triggered downregulation of K2p 1.1 gene in primary sensory neurons contributes to paclitaxel-induced neuropathic pain. Int J Cancer . https://doi.org/10.1002/ijc.32155 [doi].

8. Bourtchuladze R, Frenguelli B, Blendy J, Cioffi D, Schutz G, Silva AJ (1994) Deficient long-term memory in mice with a targeted mutation of the cAMP-responsive element-binding protein. Cell 79: 59-68. 0092-8674(94)90400-6 [pii];https://doi.org/10.1016/ 0092-8674(94)90400-6 [doi].

9. Pugazhenthi S, Wang M, Pham S, Sze CI, Eckman CB (2011) Downregulation of CREB expression in Alzheimer's brain and in Abeta-treated rat hippocampal neurons. Mol Neurodegener 6: 60 . 1750-1326-6-60 [pii];https://doi.org/10.1186/1750-1326-6-60 [doi].

10. Silva AJ, Kogan JH, Frankland PW, Kida S (1998) CREB and memory. Annu Rev Neurosci 21: 127-148. https://doi.org/10. 1146/annurev.neuro.21.1.127 [doi].

11. Segond von BG, Konig C, Patzer J, Eitner A, Leuchtweis J, Ebbinghaus M, Boettger MK, Schaible HG (2016) Long-Lasting Activation of the Transcription Factor CREB in Sensory Neurons by Interleukin-1beta During Antigen-Induced Arthritis in Rats: A Mechanism of Persistent Arthritis Pain? Arthritis Rheumatol 68: 532-541. https://doi.org/10.1002/art.39445 [doi].

12. Ma W, Zheng WH, Powell K, Jhamandas K, Quirion R (2001) Chronic morphine exposure increases the phosphorylation of MAP kinases and the transcription factor CREB in dorsal root ganglion neurons: an in vitro and in vivo study. Eur J Neurosci 14: 1091-1104. 1731 [pii];https://doi.org/10.1046/j.0953-816x.2001. 01731.x [doi].

13. Purves-Tyson TD, Keast JR (2004) Rapid actions of estradiol on cyclic amp response-element binding protein phosphorylation in dorsal root ganglion neurons. Neuroscience 129: 629-637. S03064522(04)00732-8 [pii];https://doi.org/10.1016/j.neuroscience. 2004.08.019 [doi].

14. Xiao C, Zhang L, Cheng QP, Zhang LC (2008) The activation of extracellular signal-regulated protein kinase 5 in spinal cord and dorsal root ganglia contributes to inflammatory pain. Brain Res 1215: 76-86. S0006-8993(08)00815-9 [pii];https://doi.org/10. 1016/j.brainres.2008.03.065 [doi].

15. Dang JK, Wu Y, Cao H, Meng B, Huang CC, Chen G, Li J, Song XJ, Lian QQ (2014) Establishment of a rat model of type II diabetic neuropathic pain. Pain Med 15: 637-646. https://doi.org/10.1111/ pme.12387_1 [doi].

16. Herdegen T, Fiallos-Estrada CE, Schmid W, Bravo R, Zimmermann M (1992) The transcription factors c-JUN, JUN D and CREB, but not FOS and KROX-24, are differentially regulated in axotomized neurons following transection of rat sciatic nerve. 
Brain Res Mol Brain Res 14: 155-165. 0169-328X(92)90170-G [pii];https://doi.org/10.1016/0169-328x(92)90170-g [doi].

17. Nakanishi M, Hata K, Nagayama T, Sakurai T, Nishisho T, Wakabayashi H, Hiraga T, Ebisu S, Yoneda T (2010) Acid activation of Trpv1 leads to an up-regulation of calcitonin gene-related peptide expression in dorsal root ganglion neurons via the CaMKCREB cascade: a potential mechanism of inflammatory pain. Mol Biol Cell 21: 2568-2577. E10-01-0049 [pii];https://doi.org/10. 1091/mbc.E10-01-0049 [doi].

18. St-Jacques B, Ma W (2013) Prostaglandin E2/EP4 signalling facilitates EP4 receptor externalization in primary sensory neurons in vitro and in vivo. Pain 154: 313-323. S0304-3959(12)00618-5 [pii];https://doi.org/10.1016/j.pain.2012.11.005 [doi].

19. Shao S, Xia H, Hu M, Chen C, Fu J, Shi G, Guo Q, Zhou Y, Wang W, Shi J, Zhang T (2020) Isotalatizidine, a C19-diterpenoid alkaloid, attenuates chronic neuropathic pain through stimulating ERK/ CREB signaling pathway-mediated microglial dynorphin A expression. J Neuroinflammation 17: 13. https://doi.org/10.1186/s12974019-1696-9 [doi];10.1186/s12974-019-1696-9 [pii].

20. Liu X, Zhang L, Jin L, Tan Y, Li W, Tang J (2018) HCN2 contributes to oxaliplatin-induced neuropathic pain through activation of the CaMKII/CREB cascade in spinal neurons. Mol Pain 14: 1744806918778490. https://doi.org/10.1177/1744806918778490 [doi].

21. Jones DS, Jenney AP, Joughin BA, Sorger PK, Lauffenburger DA (2018) Inflammatory but not mitogenic contexts prime synovial fibroblasts for compensatory signaling responses to $\mathrm{p} 38$ inhibition. Sci Signal 11. 11/520/eaal1601 [pii];https://doi.org/10.1126/ scisignal.aal1601 [doi].

22. Gu X, Bo J, Zhang W, Sun X, Zhang J, Yang Y, Ma Z (2013) Intrathecal administration of cyclic AMP response elementbinding protein-antisense oligonucleotide attenuates neuropathic pain after peripheral nerve injury and decreases the expression of N-methyl-D-aspartic receptors in mice. Oncol Rep 30: 391-398. https://doi.org/10.3892/or.2013.2437 [doi].

23. Tao T, Wei MY, Guo XW, Zhang J, Yang LY, Zheng H (2019) Modulating cAMP responsive element binding protein 1 attenuates functional and behavioural deficits in rat model of neuropathic pain. Eur Rev Med Pharmacol Sci 23: 2602-2611. https://doi.org/10. 26355/eurrev_201903_17410[doi].

24. Xu B, Cao J, Z̄hang J, Jia S, Wu S, Mo K, Wei G, Liang L, Miao X, Bekker A, Tao YX (2017) Role of MicroRNA-143 in Nerve InjuryInduced Upregulation of Dnmt3a Expression in Primary Sensory Neurons. Front Mol Neurosci 10: 350. https://doi.org/10.3389/ fnmol.2017.00350 [doi].

25. Xu JT, Zhou X, Zhao X, Ligons D, Tiwari V, Lee CY, Atianjoh FE, Liang L, Zang W, Njoku D, Raja SN, Yaster M, Tao YX (2014) Opioid receptor-triggered spinal mTORC1 activation contributes to morphine tolerance and hyperalgesia. J Clin Invest 124: 592-603. S0006-8993(10)00818-8 [pii];https://doi.org/10.1016/j.brainres. 2010.04.010 [doi].

26. Zhang J, Liang L, Miao X, Wu S, Cao J, Tao B, Mao Q, Mo K, Xiong M, Lutz BM, Bekker A, Tao YX (2016) Contribution of the Suppressor of Variegation 3-9 Homolog 1 in Dorsal Root Ganglia and Spinal Cord Dorsal Horn to Nerve Injury-induced Nociceptive Hypersensitivity. Anesthesiology 125: 765-778. https://doi.org/10. 1097/ALN.0000000000001261 [doi].

27. Zhao JY, Liang L, Gu X, Li Z, Wu S, Sun L, Atianjoh FE, Feng J, Mo K, Jia S, Lutz BM, Bekker A, Nestler EJ, Tao YX (2017) DNA methyltransferase DNMT3a contributes to neuropathic pain by repressing Kcna2 in primary afferent neurons. Nat Commun 8: 14712. ncomms14712 [pii];https://doi.org/10.1038/ncomms14712 [doi].

28. Zhao X, Tang Z, Zhang H, Atianjoh FE, Zhao JY, Liang L, Wang W, Guan X, Kao SC, Tiwari V, Gao YJ, Hoffman PN, Cui H, Li M, Dong X, Tao YX (2013) A long noncoding RNA contributes to neuropathic pain by silencing Kcna2 in primary afferent neurons. Nat Neurosci 16: 1024-1031. nn.3438 [pii];https://doi.org/10.1038/ nn. 3438 [doi].

29. Li Z, Gu X, Sun L, Wu S, Liang L, Cao J, Lutz BM, Bekker A, Zhang W, Tao YX (2015) Dorsal root ganglion myeloid zinc finger protein 1 contributes to neuropathic pain after peripheral nerve trauma. Pain 156: 711-721. https://doi.org/10.1097/j.pain. 0000000000000103 [doi].

30. Li Z, Mao Y, Liang L, Wu S, Yuan J, Mo K, Cai W, Mao Q, Cao J, Bekker A, Zhang W, Tao YX (2017) The transcription factor $\mathrm{C} / \mathrm{EBPbeta}$ in the dorsal root ganglion contributes to peripheral nerve trauma-induced nociceptive hypersensitivity. Sci Signal 10: eaam5345. 10/487/eaam5345 [pii];https://doi.org/10.1126/ scisignal.aam5345 [doi].

31. Mo K, Wu S, Gu X, Xiong M, Cai W, Atianjoh FE, Jobe EE, Zhao $\mathrm{X}$, Tu WF, Tao YX (2018) MBD1 Contributes to the Genesis of Acute Pain and Neuropathic Pain by Epigenetic Silencing of Oprm 1 and Kcna2 Genes in Primary Sensory Neurons. J Neurosci 38: 9883-9899. JNEUROSCI.0880-18.2018 [pii];https:// doi.org/10.1523/JNEUROSCI.0880-18.2018 [doi].

32. Yuan J, Wen J, Wu S, Mao Y, Mo K, Li Z, Su S, Gu H, Ai Y, Bekker A, Zhang W, Tao YX (2019) Contribution of dorsal root ganglion octamer transcription factor 1 to neuropathic pain after peripheral nerve injury. Pain 160: 375-384. https://doi.org/10. 1097/j.pain.0000000000001405 [doi].

33. Sun L, Zhao JY, Gu X, Liang L, Wu S, Mo K, Feng J, Guo W, Zhang J, Bekker A, Zhao X, Nestler EJ, Tao YX (2017) Nerve injury-induced epigenetic silencing of opioid receptors controlled by DNMT3a in primary afferent neurons. Pain 158: 1153-1165. https://doi.org/10.1097/j.pain.0000000000000894 [doi].

34. Sun L, Gu X, Pan Z, Guo X, Liu J, Atianjoh FE, Wu S, Mo K, Xu B, Liang L, Bekker A, Tao YX (2019) Contribution of DNMT1 to neuropathic pain genesis partially through epigenetically repressing Kcna2 in primary afferent neurons. J Neurosci JNEUROSCI.0695-19.2019 [pii];https://doi.org/10.1523/ JNEUROSCI.0695-19.2019 [doi].

35. Fan L, Guan X, Wang W, Zhao JY, Zhang H, Tiwari V, Hoffman PN, Li M, Tao YX (2014) Impaired neuropathic pain and preserved acute pain in rats overexpressing voltage-gated potassium channel subunit Kv1.2 in primary afferent neurons. Mol Pain 10: 8. 17448069-10-8 [pii];https://doi.org/10.1186/1744-8069-10-8 [doi].

36. Lonze BE, Ginty DD (2002) Function and regulation of CREB family transcription factors in the nervous system. Neuron 35: 605-623. S0896627302008280 [pii];https://doi.org/10.1016/ s0896-6273(02)00828-0 [doi].

37. Herdegen T, Fiallos-Estrada C, Schmid W, Bravo R, Zimmermann M (1992) The transcription factor CREB, but not immediate-early gene encoded proteins, is expressed in activated microglia of lumbar spinal cord following sciatic nerve transection in the rat. Neurosci Lett 142: 57-61.

38. Liang L, Lutz BM, Bekker A, Tao YX (2015) Epigenetic regulation of chronic pain. Epigenomics 7: 235-245. https://doi.org/10.2217/ epi.14.75 [doi].

39. Poetsch AR, Plass C (2011) Transcriptional regulation by DNA methylation. Cancer Treat Rev 37 Suppl 1: S8-12.

40. Turek-Plewa J, Jagodzinski PP (2005) The role of mammalian DNA methyltransferases in the regulation of gene expression. Cell Mol Biol Lett 10: 631-647.

41. Liang Y, Liu Y, Hou B, Zhang W, Liu M, Sun YE, Ma Z, Gu X (2016) CREB-regulated transcription coactivator 1 enhances CREB-dependent gene expression in spinal cord to maintain the bone cancer pain in mice. Mol Pain 12. 12/0/1744806916641679 [pii];https://doi.org/10.1177/1744806916641679 [doi].

42. Wang H, Morishita Y, Miura D, Naranjo JR, Kida S, Zhuo M (2012) Roles of CREB in the regulation of FMRP by group I metabotropic glutamate receptors in cingulate cortex. Mol Brain 5: 27. 
1756-6606-5-27 [pii];https://doi.org/10.1186/1756-6606-5-27 [doi].

43. Fink DJ, Wechuck J, Mata M, Glorioso JC, Goss J, Krisky D, Wolfe D (2011) Gene therapy for pain: results of a phase I clinical trial. Ann Neurol 70: 207-212. https://doi.org/10.1002/ana.22446 [doi].

44. Wolfe D, Mata M, Fink DJ (2012) Targeted drug delivery to the peripheral nervous system using gene therapy. Neurosci Lett 527:
85-89. S0304-3940(12)00581-2 [pii];https://doi.org/10.1016/j. neulet.2012.04.047 [doi].

Publisher's Note Springer Nature remains neutral with regard to jurisdictional claims in published maps and institutional affiliations. 